\title{
Sensory Nerves in Adult Rats Regenerate and Restore Sensory Function to the Skin Independently of Endogenous NGF
}

\author{
Jack Diamond, Anne Foerster, Michael Holmes, and Michael Coughlin \\ Department of Biomedical Science, McMaster University, Hamilton, Ontario, Canada L8N 3Z5
}

We have investigated the possible roles of NGF, and of impulse activity, in the regeneration of sensory nerves. Unexpectedly, the ability of crushed axons to regrow and to restore functional recovery of three sensory modalities in adult rat skin (A $\alpha$-mediated touch, A $\delta$-mediated mechanonociception, and $\mathrm{C}$-fiber-mediated heat nociception) was totally unaffected by anti-NGF treatment. This finding applied even when the anti-NGF dosage was almost eight times that which entirely blocked collateral sprouting of the undamaged axons of both classes of nociceptive nerves (the A $\alpha$-axons do not sprout in adult animals). In the same antiNGF-treated animal, regeneration would proceed normally on the one side, while collateral sprouting was prevented on the other. Light microscopic and EM examination revealed that in the denervated skin the regenerating axons utilized the same dermal perineurial pathways followed by collaterally sprouting axons. Regeneration within these antibodyaccessible pathways progressed normally during anti-NGF treatment, extending $1-2 \mathrm{~cm}$ beyond the former field borders, that is, into territory whose invasion by collaterally sprouting axons was totally blocked. The blood-nerve barrier is absent within the degenerating peripheral nerve trunk, a putative NGF source for regenerating fibers but not for sprouting ones. The NGF-independent regeneration was also found to be unaffected when putative spinal cord sources of NGF were eliminated by dorsal root excision. Anti-NGF treatment also failed to block regeneration across $4 \mathrm{~mm}$ excision gaps in the nerve trunk. The daily anti-NGF regime continued to be effective for at least 8 weeks, at which time newly evoked collateral sprouting could still be blocked. Exogenous NGF, in doses that evoke collateral sprouting de novo in normal skin, failed to influence regeneration. Finally, an electrical stimulus regime, which markedly reduces the latency of collateral sprouting, failed to affect the time to arrival of regenerating axons at the skin, or the rate of their arborization in it.

We conclude that, in striking contrast to their collateral sprouting, the regeneration of nociceptive axons occurs in-

\footnotetext{
Received July 26, 1991; revised Nov. 11, 1991; accepted Nov. 18, 1991

This work was supported by the MRC (Canada) and by the MS Society of Canada. Partial support also came through the Canadian Centre of Excellence for Neural Regeneration and Functional Recovery. We are grateful to Bert Vishcau and Evi Pertens for their participation in the EM studies, to Jolanta Stanisz for her preparation of the NGF and antiserum to NGF, and to Andrew Gloster, Yvonne Kril, and Jim Fawcett for their comments on the manuscript.

Correspondence should be addressed to Dr. Jack Diamond, Professor and Head, Division of Neuroscience, Department of Biomedical Sciences, McMaster University, 1200 Main Street West, Hamilton, Ontario, Canada L8N $3 Z 5$.

Copyright (C) 1992 Society for Neuroscience 0270-6474/92/121.467-10\$05.00/0
}

dependently of endogenous NGF and is unaffected by impulse activity. These findings further support the proposal that these two growth behaviors have basically different biological functions in the organism.

In the preceding companion article (Diamond et al., 1992a) evidence was presented implicating endogenous $\mathrm{NGF}$ as an essential requirement for the collateral sprouting of myelinated and unmyelinated nociceptive fibers in the skin of adult rats. Collateral sprouting is a growth characteristic of undamaged nerves, though not all nerve modalities may express it, even in the PNS (e.g., A $\alpha$-axons fail to sprout in the adult mammal; see Diamond et al., 1992b). All peripheral nerves, however, exhibit a second type of nerve growth, namely regeneration. Regeneration is specifically a growth response of an injured axon. NGF became an attractive candidate for the role of axonal regeneration factor, in particular for sensory nerves, when it was found that adult sensory axons can take up and retrogradely transport NGF (Stoeckel et al., 1975; Richardson and Riopelle, 1984), possibly in association with their receptors (Johnson et al., 1987), and that NGF mRNA increases markedly in degenerating nerve pathways (Heumann et al., 1987a). A hypothesis implicating Schwann cells in an NGF-dependent axonal regeneration was proposed when it was found that in nerves distal to a cut, the Schwann cells rapidly begin to express NGF rcceptors (Taniuchi et al., 1986), this expression essentially disappearing when regenerating axons arrive in the vicinity of the cells (Taniuchi et al., 1988).

The preparation and approach we used to study the NGF dependency of collateral sprouting, and how this could be influenced by impulse activity in the affected axons (Diamond et al., 1992a), lent themselves readily to the analogous study of the regeneration of the same nerves, which we now report. The results were unexpected, in view of the above observations, and especially in the light of our results on collateral sprouting. They add substantially to other differences between the two growth behaviors, with some interesting implications (e.g., Diamond, 1988).

Some of the present findings have been briefly reported previously (Diamond et al., 1987).

\section{Materials and Methods}

The essential details of the operative approaches, NGF and anti-NGF production and administration, sensory testing, and light and electron microscopic examinations were the same as those described in the preceding report (Diamond et al., 1992a). The following additional procedures were used in the present study.

Regeneration surgery. The nerves used in the regeneration studies were usually three or four of the dorsal cutaneous nerves (DCNs) on each side, and at times only the medial branch of thoracic (T) DCN 13 
a

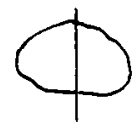

$\mathbf{x}$
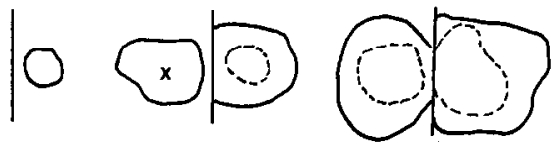

b

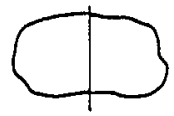

○
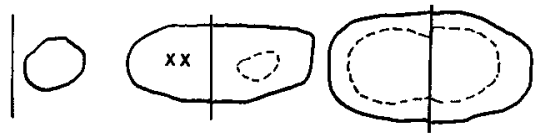

Od

2ld

28d

Figure 1. Recovery of nociceptive function by regenerating nerves in control and anti-NGF-treated animals. $a$ and $b$ show the results from two animals of the progressive recoveries of nociceptive fields (the touch fields, which also recovered, are not shown; see Results) following crush of both the right and the left $\mathrm{mDCN}$ T13. Each set of results (left to right) shows the isolated fields, mapped on the indicated days precrush $(0 \mathrm{~d})$ and postcrush $(12 \mathrm{~d}, 21 \mathrm{~d}$, and $28 \mathrm{~d})$. The two 0d outlines are the pinch fields prior to nerve section (the heat fields were not measured initially, but would have been somewhat smaller than the pinch, as shown in Fig. 6). The vertical lines show the midline, along which the initial skin incision was made for the denervation procedures. Pinchsensitive areas are shown by continuous lines, and heat-sensitive ones, by dashed lines ( $\times$ shows a single pinch-sensitive spot at $12 \mathrm{~d}$, and indicates a number of heat-sensitive spots at $21 \mathrm{~d}$ ). Animal $a$ received daily injections of control serum, and animal $b$ received injections of anti-NGF serum at the standard dosage; this anti-NGF treatment prevented collateral sprouting at the perimeter of the denervated skin (see Results).

(mDCN T13) on the left side. Crushing of selected nerves was done with specially ground smooth-jawed forceps at selected regions between the nerve exit point from the body wall and the point of entry into the skin. The forceps were applied to two or three sites about $1 \mathrm{~mm}$ apart, for three episodes of $30 \mathrm{sec}$ each, a procedure that flattened the nerve trunk and its associated blood vessels to a transparent film. The completeness of the crush (a critically important concern in experiments of this kind) was verified by reanesthetizing the animal within $2 \mathrm{~d}$ and testing the appropriate regions of the skin for pinch sensitivity. If any sensitivity was found (a rare occurrence), the relevant nerve trunks were reexposed and recrushed.

In some experiments the nerve trunk whose regeneration was to be studied was completely sectioned. Using a dissecting microscope, the ensheathing connective tissue was slit open with fine forceps, exposing the nerve trunk, which was cut with scissors; the site of nerve section was marked by a loose loop of thread or a touch of India ink. In one group of animals, a $4 \mathrm{~mm}$ section of the nerve trunk was excised, leaving the two cut ends lying loosely within the connective tissue sheath.

When the selected nerve to be studied was mDCN T13, it was first isolated on one side of the animal and the pinch, heat, and often the touch fields were mapped as described in the preceding report (Diamond et al., 1992a). The nerve was then crushed at a measured distance from the skin and allowed to regenerate. In other studies, a midline incision was made so that selected DCNs could be crushed (or cut) on both sides, and their subsequent regeneration followed. In these animals only the pinch fields, and sometimes the heat fields, were mapped prior to the nerve treatment. In all experiments one group of animals received daily injections of anti-NGF serum, and a second group received daily injections of control serum; often a third group of animals was included that received no injections.

Rhizotomies. Animals were deeply anesthetized with sodium pentobarbital $(60 \mathrm{mg} / \mathrm{kg})$ and injected with a long-acting penicillin-based antibiotic. Following midline incision, the skin was reflected in the mid thoracic area, vertebrae T10-T12 were freed of muscle between the spines and lateral processes and the bone was nibbled away with fine rongeurs. A slit was made in the meninges and a glass hook was used to loosen the dorsal roots on the left side. Selected roots were cut with fine scissors, and their designation was confirmed by stimulating identified DCNs and noting the presence or absence of a cutaneus trunci muscle (CTM) reflex response (Theriault and Diamond, 1988). The dura was then sutured and covered with an absorbable hemostatic pad, the musculature was approximated at the midline, and the skin was sutured.

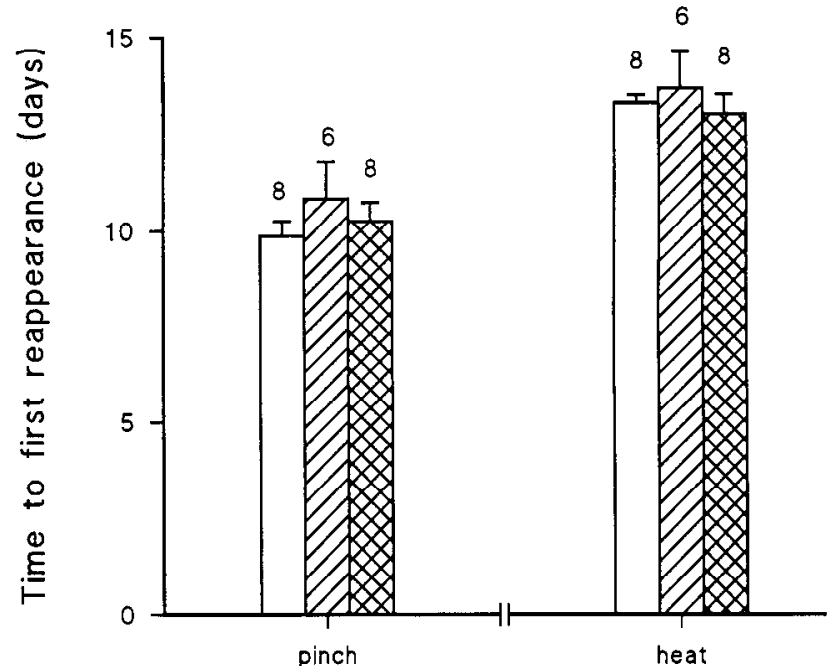

Figure 2. Neither NGF nor anti-NGF affect time to onset of nociceptive functional recovery by axonal regeneration. The ordinate shows the time ( \pm SEM) to the first signs of recovery of pinch and heat nociception in denervated skin achieved by regenerating nerves for three groups of animals: one group (hatched histograms) received daily injections of $\mathrm{NGF}(50 \mu \mathrm{g})$, a second group received anti-NGF injections (crosshatched histograms), and a third group received control serum (open histograms). The results were not significantly different for all three groups $(p \geqq 0.05$, ANOVA). Numbers of animals in each group are indicated above error bars in this figure and in Figs. 3, 7, and 8.

The gait and general behavior of the animals were usually normal immediately following recovery; occasionally the ipsilateral hind limb developed a limp some days later, but this always disappeared after about 1 week.

Electrical stimulation. Platinum wirc clcctrodes, across which the nerve was laid, were used to deliver square wave pulses from a conventional low-impedance pulse generator (Devices). The stimulation $(20 \mathrm{~Hz}, 10 \mathrm{~min}$ ) was done prior to the nerve being crushed to evoke regeneration, and the stimulus strength was selected to be supramaximal for activation of both the C-and the A-fibers (Theriault and Diamond, 1988). The impulses were allowed to conduct only centrally by coldblocking the nerve at a point distal to the electrodes, achieved by application of ice-cold saline for a few minutes. The crushing procedure would itself excite afferent impulses, so in both the control and the stimulated animals crushing was carried out at a region of the nerve distal to an applied cold block. The effectiveness of the block was indicated by the absence, in the nerve central to the blocked region, of recordable discharges in response to light touch, and by the failure of the nerve crush to evoke the CTM reflex.

\section{Results}

\section{Regeneration after nerve crush}

The first signs of recovery of sensory function attributable to regeneration were always observed within the area originally supplied by that nerve. Because of unavoidable variations in the exact length of the regencration pathway in different animals, and the spacing of the testing intervals ( $2 \mathrm{~d}$ up to the time when the first positive response was observed, and 3-5 d thereafter), the recovery rates we observed are approximate (see below). After nerve section these rates were sometimes obviously less, and always more variable, than those after nerve crush. The following description comes from the crush studies.

The return of sensory function to the skin (Fig. 1a) was first detected 8-14 d postcrush, and usually included light touch, signaled by the large myelinated (A $\alpha$ ) axons (Burgess et al., 1974; Jackson and Diamond, 1984), and pinch sensitivity, signaled by thinly myelinated (A $\delta$ ) axons (Nixon et al., 1984). In most animals, early electrical recordings to test for first appearance 
Table 1. Axonal regeneration into the distal nerve: fibers in distal segment as percentage of proximal (mean \pm SEM)

\begin{tabular}{|c|c|c|c|}
\hline \multirow[b]{2}{*}{ Treatment } & \multicolumn{3}{|l|}{ Fiber } \\
\hline & $\mathrm{A} \alpha$ & $\mathrm{A} \delta$ & $\mathrm{C}$ \\
\hline Control & $97.0 \pm 8.0$ & $93.0 \pm 8.0$ & $91.0 \pm 10.0$ \\
\hline Anti-NGF & $101.0 \pm 8.0$ & $94.0 \pm 9.0$ & $107.0 \pm 13.0$ \\
\hline NGF & $100.0 \pm 5.0$ & $93.0 \pm 5.0$ & $128.0 \pm 14.0$ \\
\hline
\end{tabular}

Counts were made of the total myelinated axonal populations within the entire mDCN T13 nerve trunk, at regions $7-10 \mathrm{~mm}$ above the site of the nerve crush and 5-10 mm distal to it. Photomontages were constructed from toluidine bluestained semithin sections for this purpose. The nerves were taken from animals 1-2 months postcrush, when cutaneous sensory function had been fully restored to the initially denervated skin by the regenerating fibers of mDCN T13. A $\alpha$ fibers had axis cylinder diameters of $>3 \mu \mathrm{m}$ and myelin sheaths $>0.2 \mu \mathrm{m}$ thick; smaller myelinated axons were scored as $\mathrm{A} \delta$. The ratio $\mathrm{C}$-fibers:myelinated fibers was obtained from electron micrographs of the nerve, and the absolute number of $\mathrm{C}$-fibers was then calculated, using the myelinated fiber counts described above. Regeneration success in this histological study was evaluated by calculating the percentage of the proximal fibers that appeared in the distal nerve trunk. There was no significant difference between any groups for each of the fiber types $(p>0.05$, Student's $t$ test, ANOVA).

of the touch modality were avoided so as not to risk damaging the more slowly regenerating axons within the nerve (the touch fields are not included in Fig. 1, but an example appears in Fig. $6)$. The last modality to reappear (12-15 d) was almost invariably heat nociception, subserved by unmyelinated C-fibers (Doucette and Diamond, 1987; Doucette et al., 1987). The heat field expanded at the slowest rate of the three modalities studied. We did not make systematic studies on the maximum extent of reinnervation. However, both the pinch- and the heat-sensitive areas would not only reconstitute the original fields, but after some 4-5 weeks growth they could significantly exceed their original sizes (by a factor of 2 or more; see Fig. 8). The touch field usually stabilized when it only slightly exceeded its initial area, although in a few animals a clear enlargement had occurred (cf. Yasargil et al., 1988).

A quantitative presentation of the findings on the times to onset of nociceptive function in denervated skin following nerve crush, and the subsequent development of nociceptive fields, is described later (see Figs. 5, 6).

\section{Testing for anti-NGF effects}

Because of the findings (Diamond et al., 1992a) on the NGF dependency of the collateral sprouting of both myelinated and unmyelinated nociceptive axons, we were especially interested in the effects of anti-NGF treatment on the regeneration-related recovery of nociceptive function in denervated skin. Qualitatively, such treatment caused no obvious impairment in sensory recovery (Fig. $1 b$ ). We then measured the time to the onset of nociceptive sensitivity (Fig. 2), and the time to (approximate) restoration of the original field size (Fig. 3; the midline was taken as the medial limit in the experiments in which midline incisions were used). The results are illustrated in the crosshatched and open histograms of Figures 2 and 3. There were no differences in the overall regeneration rates between experimental and control groups. Indeed, the anti-NGF treatment did not even appear to have retarded the recovery of nociceptive function by the regenerating axons.

In a limited study, the success of axonal regeneration beyond the crush was also evaluated by measuring the proportion of

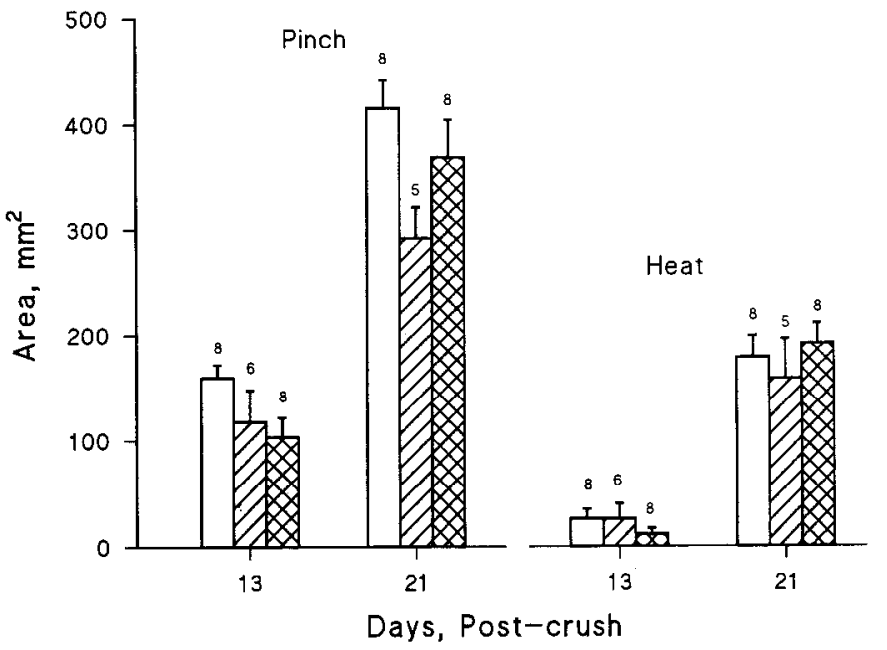

Figure 3. Nociceptive fields are progressively restored by axonal regeneration independently of concomitant NGF or anti-NGF treatment. Shown on the ordinate are the pinch- and heat-nociceptive field areas $( \pm$ SEM) restored by the axonal regeneration described in Figure 2 (conventions are as in Fig. 2). Two time points were used for the mapping, $13 \mathrm{~d}$ and $21 \mathrm{~d}$ after the original nerve crush, and the three injection regimes were maintained throughout. There were no significant differences ( $p>0.05$ ANOVA) between any of the three groups (NGF treated, anti-NGF treated, and the control group) at each time point.

the proximal fiber population that was present in the distal segment when cutaneous sensory function had returned. No significant differences were found, either for myelinated or unmyelinated fibers, between control animals and animals that received anti-NGF treatment throughout the regeneration process (Table 1).

\section{Was the dose of anti-NGF adequate?}

Conceivably, the level of anti-NGF required to prevent regeneration might exceed that which prevents collateral sprouting. We examined this possibility by increasing the antiserum dosage, first up to three times, and in two animals six times, that which we used routinely to prevent sprouting. Since this routine dosage was itself up to $40 \%$ greater than the minimal dose capable of blocking sprouting (see Diamond et al., 1992a), the largest dosage of anti-NGF examined was about eightfold that capable of totally preventing collateral sprouting. We looked not only for a failure of regeneration, but also for a slowing of the apparent regeneration rate. We did not detect either of these effects (Table 2).

\section{Were the regenerating axons accessible to the injected antibodies?}

This is a critically important consideration. The key finding came from histological examination of the skin. Silver staining always revealed the regenerating axons to be growing within the perineurial pathways that were denuded of axons by the original denervations (Fig. 4). As described in the preceding report (Diamond et al., 1992a), when collateral growth is occurring within these pathways, it is always totally prevented by the anti-NGF treatment. Other reasons for rejecting the possibility that the regenerating fibers were inaccessible to the anti-NGF treatment are discussed later. 

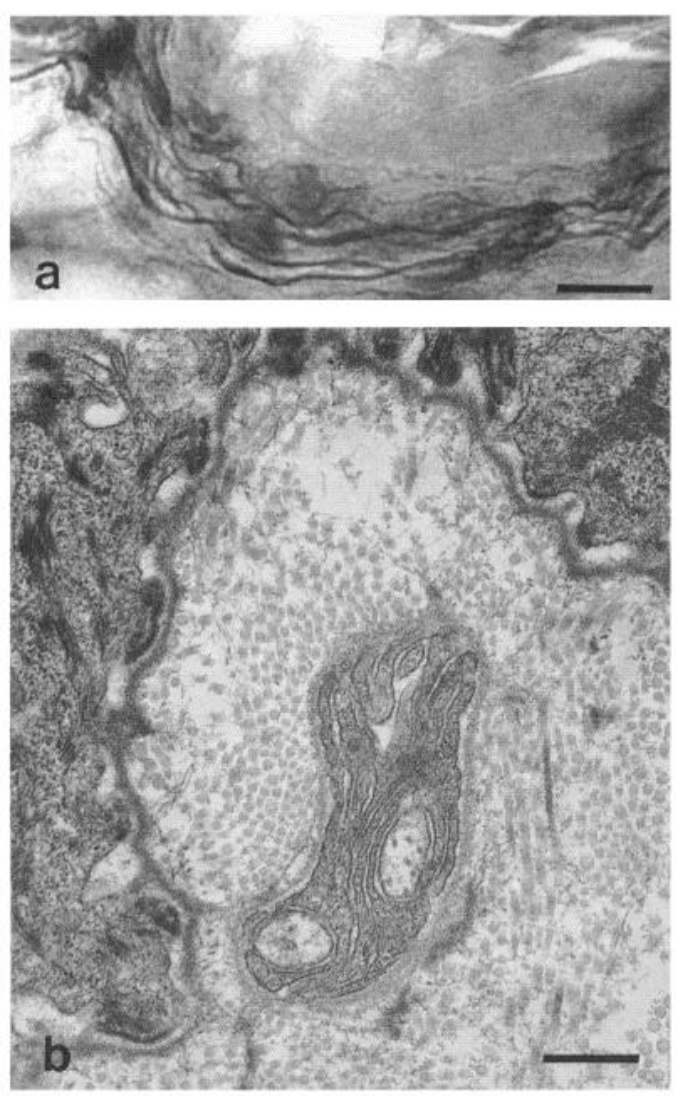

Figure 4. Pathways followed by regenerating axons. $a$ and $b$ show typical light and electron micrographs, respectively, of skin that had been totally denervated $28 \mathrm{~d}$ earlier, but whose pinch and heat sensitivity had been restored by regenerating axons. The silver stained axons in $a$ occupy a perineurial tube just as in normal skin. In $b$ unmyelinated axon profiles are now seen in a Schwann tube lying within an epidermal gutter, that would have been devoid of axons earlier (cf. Fig. 3 in Diamond et al., 1992a). Scale bars: $a, 20 \mu \mathrm{m} ; b, 0.5 \mu \mathrm{m}$.

\section{Did the daily anti-NGF treatment retain its effectiveness over the period during which regeneration was followed?}

We used the collateral sprouting paradigm to examine the possibility that an immunological response to the repeated injections of anti-NGF serum might have developed in time, negating the effects of the treatment. The regenerating fibers could take many weeks before they arrived at and invaded the denervated skin outside the original field borders. However, collateral sprouting into this identical region of skin could be held up for many weeks by anti-NGF treatment, resuming when treatment was discontinued (Diamond et al., 1992a). A direct test for the continued effectiveness of chronic anti-NGF administration was made by giving daily injections for almost 11 weeks. During the eighth week of this treatment regime, a sensory field was isolated and the animal was examined for collateral sprouting thereafter (see Diamond et al., 1992a). No collateral sprouting occurred during the entire period of the injections.

\section{The "NGF transfer" hypothesis}

By studying sectioned nerves, rather than crushed nerves, we tried to examine more rigorously the hypothesis that axonal regeneration is supported by a transfer of NGF from the Schwann cells of degenerating peripheral nerves to the NGF receptors on the regenerating axons (Taniuchi et al., 1986). Neuritic outgrowths from the end of a cut nerve would not, at least initially, be contained within the interior of endoneurial cylinders (Allt, 1976). In some animals, we excised a $4 \mathrm{~mm}$ length of the cutaneous nerve, including its epineurium, through an incision in the surrounding connective tissue sheath; this sheath provided a pathway for the regenerating neurites to reach the degenerating nerve downstream. Daily injections of anti-NGF or control sera were begun on the day of the nerve cut or segment excision. Due to the relatively small number of animals involved in this study, and the problems introduced by the tendency of the denervated skin to scar in anti-NGF-treated animals (Diamond et al., 1992a), there was a large variation in the results; thus, we might not have detected that some recoveries may have been slightly delayed, or slightly impaired, in the anti-NGF-treated animals as compared to the controls. The data we obtained, however (Table 3), gave no convincing indication that the antiNGF treatment per se reduced the ability of the cut axons to regenerate to the skin and restore nociceptive function.

\section{Could the regenerating axons be responding to NGF acquired by way of the central projections of the sensory neurons?}

We dealt with this possibility by separating the parent cell from the spinal cord by dorsal rhizotomy. A problem here was that the reflex response used to demonstrate the presence of nociceptive endings in the skin is disallowed by decentralizing the neurons. We took advantage, therefore, of a direct means of

Table 2. Recovery times are compared for regenerating nerves to restore sensory function in contro animals, and in animals treated with augmented levels of anti-NGF

\begin{tabular}{|c|c|c|c|}
\hline Group & $\begin{array}{l}\text { First pinch } \\
\text { response }(d)\end{array}$ & $\begin{array}{l}\text { First heat } \\
\text { response (d) }\end{array}$ & $\begin{array}{l}\text { Behavioral } \\
\text { fields } \\
\text { completely } \\
\text { reestab- } \\
\text { lished (d) }\end{array}$ \\
\hline $3 \times$ anti-NGF $(n=4)$ & between 8 and 20 & $14-27$ & $30-35$ \\
\hline Crush close to skin, control serum $(n=3)$ & between 5 and 10 & between 5 and 30 & by $40 \mathrm{~d}$ \\
\hline Crush close to skin, $+6 \times$ anti-NGF $(n=2)$ & between 5 and 10 & between 10 and 30 & by $40 \mathrm{~d}$ \\
\hline
\end{tabular}

Levels of anti-NGF in one group were increased to $3 \times$, and in another group to $6 \times$, that used to prevent collateral sprouting. The animals of the latter group, and the controls for these, had the nerve crushed close to the skin. In the group with the $3 \times$ anti-NGF dose, the nerves were crushed $1-2 \mathrm{~cm}$ more centrally. The use of "between" indicates that response had not returned by the shorter time and had all returned by, possibly a few days earlier than, the longer time. The inclusive numbers indicate that at least one recovery had occurred by the shorter time and all had occurred by the longer time. The values of the control serum group were virtually identical to those of uninjected animals. 

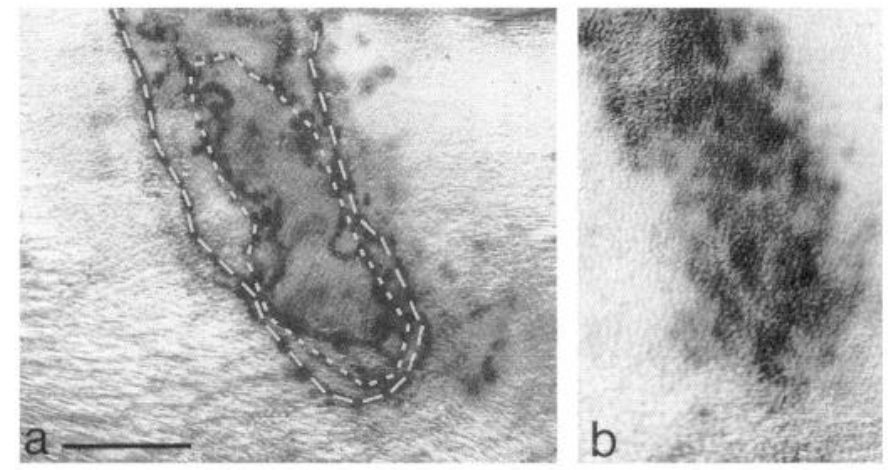

Figure 5. Sensory C-fibers regenerate after dorsal rhizotomy. $a$ and $b$ both show extravasation of Evans blue into the skin as a consequence of electrical excitation of the entire DCN T13 in two different rats (see Results). $a$ was a normal nerve, and $b$, a nerve that had been crushed $35 \mathrm{~d}$ earlier and allowed to regenerate. The dorsal roots in animal $a$ were intact; in animal $b$ the T10-L2 dorsal roots had been cut, and this animal received the standard daily anti-NGF treatment throughout the entire course of the regeneration. Prior to the Evans blue test, a mapping was done in animal $a$ to identify the pinch field (dashed outline) and the touch field (dotted outline); in this animal the border of the latter field was very close to that of the heat field, which is not shown. As a result of the mapping procedure, some extravasation of Evans blue had occurred outside the clearly identifiable denser area of extravasation that was evoked by the electrical stimulation. The touch-sensitive area in animal $b$ is not shown, but it was found to be approximately coextensive with the area of Evans blue extravasation. Scale bar, $10 \mathrm{~mm}$.

demonstrating the presence of nociceptive C-fiber terminals, the Evans blue response (Kenins, 1981), which is described in the preceding report (Diamond et al., 1992a). The "Evans blue field" in skin is normally coextensive with the nociceptive heat field (Doucette and Diamond, 1987; see Fig. 5a). Dorsal cutaneous nerves, whose dorsal roots had been ablated as described in Materials and Methods, were antidromically excited at selected times after being crushed. The results showed that the decentralized $\mathrm{C}$-fibers in such nerves regenerated widely into denervated skin, apparently in much the same manner as they did when the dorsal roots were intact. An essentially similar regeneration occurred in animals receiving coincident anti-NGF treatment (Fig. $5 b$ ). This result was especially convincing given that Evans blue responses eventually become reduced in anti-

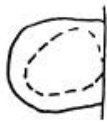

0

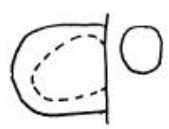

14d

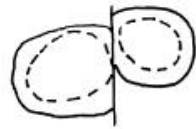

2Id

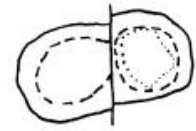

$28 d$
Figure 6. Anti-NGF treatment differentiates between regeneration and collateral sprouting in the same animal. The paradigm used here was to make a midline incision, then isolate the $\mathrm{mDCN}$ T13 fields on both sides (see Diamond et al., 1992a). The diagram on the left $(O d)$ shows the pinch (continuous line) and heat (dashed line) fields immediately following denervation of the surrounding skin. When these mappings were completed, the mDCN T13 on the right side was crushed (eliminating all sensitivity on this side), and daily anti-NGF treatment was begun. The fields were followed for the next $28 \mathrm{~d}$. By day 14, a small pinch field was restored on the right side by the regenerating axons, and by day 28 almost normal-sized pinch, heat, and light touch (dotted line) fields had been reconstituted. Throughout the entire period there was no expansion on the left side of either of the spared nociceptive fields (or the touch field, which is not shown); that is, collateral sprouting had been prevented by the anti-NGF treatment (cf. Diamond et al., 1992a).

NGF-treated animals (Diamond et al., 1992a). By recording evoked impulses from the same regenerating nerves, we confirmed an earlier report (Horch, 1979) that the large mechanosensory axons also regrew and restored apparently normal sensory function after dorsal rhizotomy. The regeneration of these axons was also not prevented by coincident anti-NGF treatment.

\section{Could the regeneration paradigm have somehow interfered with the effectiveness of the anti-NGF treatment?}

We had already noted that, while nerves regenerated in antiNGF-treated animals just as they did in controls, there was a notable difference between the two groups of animals. Within approximately 2 weeks it became evident that in the controls the perimeter of the behaviorally insensitive (denervated) area of skin had begun to reduce. This phenomenon is attributable to inward collateral sprouting of the intact nociceptive nerves supplying the surrounding skin (cf. Nixon et al., 1984). In the anti-NGF-treated group, however, there was no such change. We now made a more direct test of this differential effect on sprouting and regeneration in the same animal. In a number of

\begin{tabular}{|c|c|c|c|c|}
\hline \multicolumn{2}{|l|}{ Group } & \multirow{2}{*}{$\begin{array}{l}\text { First pinch } \\
\text { response }(\mathrm{d})\end{array}$} & \multirow{2}{*}{$\begin{array}{l}\text { First heat } \\
\text { response }(d)\end{array}$} & \multirow{2}{*}{$\begin{array}{l}\text { Complete restoration } \\
\text { of field (d) }\end{array}$} \\
\hline Nerve cut & Treatment & & & \\
\hline $\begin{array}{l}\text { Nerves cut without } \\
\text { excision }\end{array}$ & $\begin{array}{l}\text { Control serum } \\
(n=4)\end{array}$ & $<14$ & $14-22$ & $23-30$ \\
\hline $\begin{array}{l}\text { Nerves cut without } \\
\text { excision }\end{array}$ & $\begin{array}{l}\text { Anti-NGF } \\
\quad(n=3)\end{array}$ & $<14$ & $14-22$ & $\leq 30$ \\
\hline $4 \mathrm{~mm}$ of nerve excised & $\begin{array}{l}\text { Control serum } \\
\quad(n=4)\end{array}$ & $\begin{array}{l}12-50 \\
4 \text { out of } 4\end{array}$ & $\begin{array}{l}40-60 \\
3 \text { out of } 4 \\
\text { (1 failure) }\end{array}$ & $\begin{array}{l}40-60 \\
3 \text { out of } 4 \\
\text { ( } 1 \text { failure) }\end{array}$ \\
\hline $4 \mathrm{~mm}$ of nerve excised & $\begin{array}{l}\text { Anti-NGF } \\
\qquad(n=4)^{a}\end{array}$ & $\begin{array}{l}12-48 \\
3 \text { out of } 4 \\
\text { (1 failure) }\end{array}$ & $\begin{array}{l}39-60 \\
2 \text { out of } 3 \\
\text { (1 failure) }\end{array}$ & $\begin{array}{l}60 \\
\text { (other two below } \\
\text { original size) }\end{array}$ \\
\hline
\end{tabular}

Four populations of animals were compared in this table; two of them had the nerves sectioned, and two had $4 \mathrm{~mm}$ segments of the nerve excised (see Materials and Methods). One group of each population received the standard antiNGF treatment; the other, the control serum.

${ }^{a}$ The skin of one anti-NGF treatment animal was too scarred after $45 \mathrm{~d}$ to allow further measurements to be made. 
animals a midline incision was made to create two isolated homolugous fields, one on either side, supplied, respectively, by the right and left mDCN T13. The portion of the nociceptive fields that crosses the midline is sacrificed by this procedure, but this did not affect the results. The nerve on the left remained intact, but that on the right was crushed, and daily anti-NGF treatment was begun. A typical finding is shown in Figure 6; the crushed nerve regenerated, eventually restoring all three modalities (only the nociceptive results are given), while the isolated nociceptive fields on the left failed to expand; that is, the nociceptive axons failed to sprout. In some instances therc may have been a slight extension of the isolated fields near the incision line, presumably attributable to regeneration of fibers that were cut during this operation; however, the scarring at the incision line made the mapping in that region uncertain.

\section{Regeneration was unaffected by concomitant NGF administration}

In a number of experiments NGF $(50 \mu \mathrm{g})$ was administered to the animal daily for up to $21 \mathrm{~d}$ following the nerve crush, a regime that significantly increases the rate of the collateral sprouting of undamaged nociceptive fibers and evokes sprouting de novo in the skin of unoperated normal animals (see Diamond et al., 1992a). The times to the first signs of recovery of nociceptive function in the initially denervated skin (Fig. 2), and the subsequent expansion of the nociceptive fields (shown at 13 $\mathrm{d}$ and $21 \mathrm{~d}$ postcrush in Fig. 3) were not significantly different in animals treated with daily injections of NGF, anti-NGF serum, or saline. Finally, in a few of these animals we evaluated the success with which axons regenerated beyond the crush. As shown in Table 1, NGF had no significant influence on the proportion of $\mathrm{A} \alpha-, \mathrm{A} \delta-$, or $\mathrm{C}$-fibers that appeared within the degenerating peripheral nerve trunk.

\section{Impulse activity failed to accelerate regeneration}

Centrally conducted impulses in nociceptive axons advance the onset of collateral sprouting by about 5-6 d, even when the conditioning stimulation is given up to $2 \mathrm{~d}$ before fields are isolated to evoke the sprouting (Nixon et al., 1984; Doucette and Diamond, 1987). We now know that impulses appear to sensitize the neurons to the action of endogenous NGF (Diamond et al., 1992a). To determine if impulses would affect the NGF-independent regeneration of these axons, the experimental nerves were electrically stimulated for $10 \mathrm{~min}$ at $20 \mathrm{~Hz}$ prior to being crushed. Any impulses evoked by the nerve crushes were prevented from conducting centrally by cold-blocking at a point proximal to the crushed region (see Materials and Methods). Control nerves were also electrically stimulated prior to crush but, like the crush, distal to the cold block to prevent the evoked impulses from conducting centrally. The measured parameters of regeneration were (1) the times postcrush when reflex responses to skin applications of the heat probe and pinch first reappeared (this time would be largely occupied by axonal regeneration along the degenerating peripheral nerve pathway) and (2) the expansion of the nociceptive fields thereafter. Although a recovery that had been advanced by $1-2 \mathrm{~d}$ might not have been reliably detected, a $5 \mathrm{~d}$ acceleration would have been evident. There was no significant difference between the animals in which the conditioning impulses were allowed to conduct centrally, and those in which the impulses were blocked, either in the times to onset of responses (Fig. 7) or in the subsequent rates of field expansions (Fig. 8). These expansions were followed to a time when the fields were similar to, or somewhat larger than, their estimated original sizes. [The fields had not been measured initially, and the estimates were based on the mean values of the corresponding fields measured in a large control population of similar-sized animals in the studies of Nixon et al. (1984) and Doucette and Diamond (1987).] The failure of impulse activity to influence regeneration was all the more striking given that the newly appearing fields were examined at intervals to measure their expansions; thus, the neurons were subjected to repeated episodes of potentially conditioning impulse activity, in addition to the initial clectrically cvoked discharges.

\section{Discussion}

Axonal regeneration was unaffected by anti-NGF treatment After nociceptive axons were crushed, they regenerated normally during an anti-NGF treatment up to eight times greater than that shown to prevent their collateral sprouting (Diamond et al., 1992a). [A failure of anti-NGF to prevent axonal regeneration along a degenerating nerve was reported in another context by Rich et al. (1984).] The anti-NGF treatment discriminated unequivocally between regeneration and collateral sprouting evoked simultaneously in the same animal. These findings are at variance with the view that NGF makes a significant contribution to axonal regeneration (e.g., 'Taniuchi et al., 1986; Sandrock and Matthew, 1987). This view derives from a seemingly formidable array of obscrvations: (1) dorsal root ganglion (DRG) neurons have high-affinity NGF receptors (NGFR; Sutter et al., 1979); (2) Schwann cells can make NGF (Finn et al., 1986; Assouline et al., 1987; Bandtlow et al., 1987); (3) NGF levels, like those of NGF-R, increase in degenerating pathways, similarly becoming downregulated when regenerating axons arrive (Taniuchi et al., 1988); and (4) when peripheral nerves are cut and begin to degenerate, the associated Schwann cells display rapid expression of low-affinity NGF-R (Taniuchi et al., 1986) - this expression disappears when regenerating axons arrive in the same region of the nerve (Taniuchi et al., 1988). An ingenious scheme was proposed by Taniuchi et al. (1986), namely, that NGF is initially bound to the NGF-R on the Schwann cells, and then transfers to NGF-R on the regenerating axons by virtue of the differences in the binding affinities of the two receptor classes.

Could the regenerating axons, or their hypothetical sources of $N G F$, have been inaccessible to the anti-NGF treatment?

Here distinctions can be made between access of anti-NGF (1) to regenerating fibers within the skin itself, (2) to axons during their regeneration along the distal nerve pathway prior to reaching the skin, and (3) to the central projections of the originating neurons of the regeneraling peripheral axons.

(1) Dermal pathways. The most critical finding in the present study was that the regenerating axons in the skin utilized the same perineurial pathways as do collaterally sprouting axons, yet only the latter were affected by the anti-NGF treatment. During a maintained anti-NGF regime, regenerating nociceptive axons could eventually extend into denervated skin up to 1-2 $\mathrm{cm}$ beyond the original field borders. At that time, therefore, some 3-4 weeks after its denervation, these axons were growing within the identical region of skin, along the same pathways, whose invasion by collaterally sprouting fibers would have been totally blocked (for at least the same length of time). Moreover, if such an anti-NGF block was discontinued, collateral sprouting 


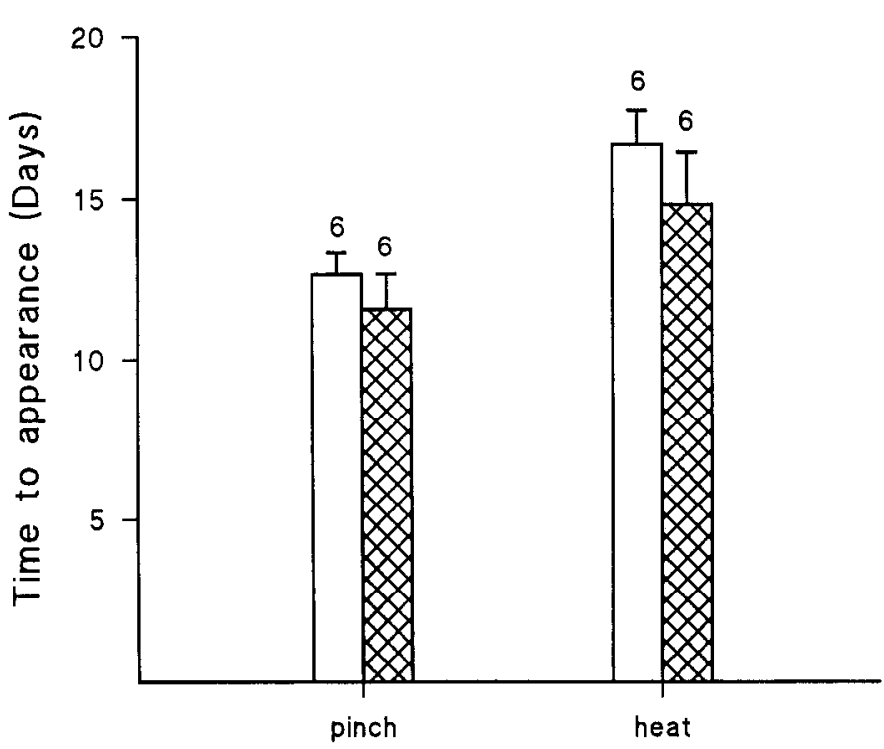

Figure 7. Axonal regeneration is unaffected by impulse activity. The ordinate shows times $( \pm$ SEM) to the first nociceptive responses following nerve crush. In one group the nerves were electrically excited just prior to their crushing (open histograms), and in the other group the nerves were similarly excited but impulse conduction centrally was blocked, as explained in Materials and Methods (crosshatched histograms).

occurred normally into the surrounding territory (Diamond et al., 1992a). The effectiveness of the anti-NGF treatment was shown to persist for injection regimes lasting for at least 11 weeks.

Within the skin then, anti-NGF administration unambiguously distinguished between regenerating and collaterally sprouting axons. Thus, for regeneration to be NGF dependent, one must postulate that the NGF sustaining it be acquired at locations central to the dermal perineurial pathways. Moreover, this NGF source would have to operate for many weeks, supporting the growth of axons whose terminals might be up to 2$3 \mathrm{~cm}$ away. The degenerating peripheral nerve trunk, and its branches up to the skin entry zone, are the only candidate locations for putative NGF sources not shared by regenerating and collaterally sprouting neurites. The findings of Campenot (1982) are pertinent here; NGF evoked elongation of sympathetic axons in vitro when it was present in the medium bathing the nerve endings, and not when it was restricted to the cell bodies and their associated proximal axons. Nevertheless, the degenerating nerve trunk has to be considered in our experiments.

(2) Distal nerve trunk. It has already been extensively proven that the blood-nerve barrier, whose effectiveness as a barrier to the movement of macromolecules from blood to the endoneurial compartment is by no means absolute or constant among animal species (Olsson, 1967, 1971), disappears in the degenerating region of a peripheral nerve below the site of a crush; moreover, the barrier does not become reconstituted until axon growth has progressed distally (Olsson, 1966; de la Motte and Allt, 1976; Sparrow and Kiernan, 1981; Seitz et al., 1989; Wadhwani et al., 1989). Antibodies therefore would be expected to gain ready access to regencrating axons within the cndoncurial compartment. This conclusion is supported by the findings of Kanje et al. (1989), who showed that antibodies to insulin-like growth factor (IGF-1), administered locally around a crush le-

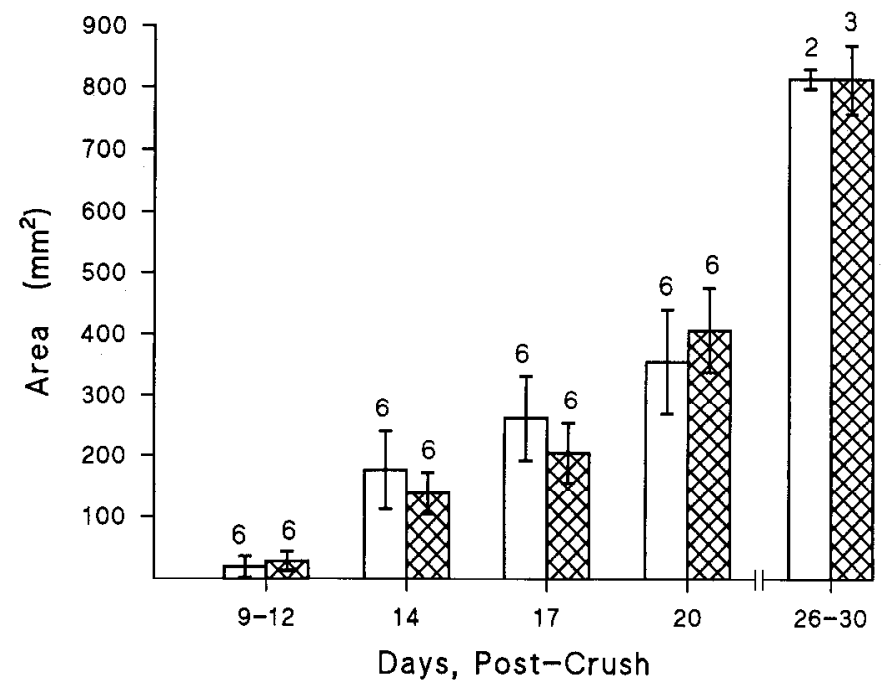

Figure 8. Field expansions due to axonal regeneration are unaffected by impulses. This shows the continuation of the experiment that provided the results for Figure 7 . The enlarging pinch fields were mapped at the times shown on the abscissa; the field areas ( \pm SEM) are shown on the ordinate. Stimulated nerves are the crosshatched histograms, and control nerves, the open histograms. By 26-30 d the fields were approximately two times larger than normal.

sion, significantly inhibited regeneration of sensory fibers in adult rats. The results we obtained after cxcision of a nerve segment are relevant here. In a number of these experiments, axons regenerated across approximately $4 \mathrm{~mm}$ of tissue devoid of the normal endoneurial pathways. Although Schwann cells would accompany and possibly precede the neurites extending across such a gap, initially at least the growing terminals would not be ensheathed by Schwann cells (Allt, 1976), and should therefore be accessible to the anti-NGF treatment. Our EM observations (J. Diamond, A. Foerster, M. Holmes, and M. Coughlin, unpublished observations) indicate that the extremities of such neurites, which were apparently growing along a basal lamina, frequently have no direct contact with Schwann cells in these circumstances. A similar finding has been reported in another regeneration paradigm (Ide and Kato, 1990). Nevertheless in our nerve excision studies the regeneration seemed not even to have been retarded, much less prevented, by the anti-NGF treatment.

The burden of the evidence then makes it very probable that the injected anti-NGF antibodies would have a significant access to the regenerating axons within the degenerating peripheral nerve. Our preceding results (Diamond et al., 1992a) prove that antibodies certainly have no difficulties penetrating in to the dermal perineurial pathways traversed by collaterally sprouting axons, which are now shown to be also the pathways utilized by regenerating ones.

(3) Central sources of NGF. The findings after rhizotomies excluded sources of NGF within the spinal cord (which would likely be inaccessible to the antibody treatment) as being responsible for supporting the regeneration of $\mathrm{C}$-fibers and of $\mathrm{A} \alpha$ axons during systemic anti-NGF administration. In the absence of a convenient marker for the presence of $A \delta$-fibers in skin (morphological approaches would not reliably distinguish between regenerating $A \alpha-$ and $A \delta$-axons), wc could not prove that the myelinated mechanonociceptive axons also regenerated normally after rhizotomy. It seems unlikely, however, that the A $\delta$ fibers would differ from $\mathrm{A} \alpha$ - and $\mathrm{C}$-fibers in this respect. 


\section{Regeneration is not NGF dependent}

We conclude that regeneration occurs essentially independently of NGF. Interestingly, the NGF available to regenerating axons within the degenerating peripheral nerve pathway is reported to be less than half that from their normal peripheral target tissues (Heumann et al., 1987b; but see Raivich et al., 1991). As discussed in the preceding report (Diamond et al., 1992a), the supply of NGF that is available to support collateral sprouting in denervated skin must be considerably higher than normal. Congruent with these findings, there is a downregulation of highaffinity NGF binding on DRG neurons after axotomy (Verge et al., 1989), but the expression of NGF-R mRNA is increased in DRG neurons whose axons are collaterally sprouting (Mearow et al., 1991). The NGF transfer hypothesis of Taniuchi et al. (1986) could presumably still be proposed to explain collateral sprouting, although this hypothesis is challenged by the findings of Raivich et al. (1991). Our results cannot, of course, exclude the possibility of a minor contribution to regeneration by endogenous NGF, or the possibility that its exogenous administration might have a beneficial action (e.g., Sandrock and Matthew, 1987; Lindsay, 1988; Rich et al., 1989; Hagg et al., 1991). Such a pharmacological action could be mediated directly via the axonal NGF-R, or even indirectly via the Schwann cell NGF-R. In the latter event, there might be an enhancement in the ability of Schwann cells either to myelinate the growing axons (cf. Hollowell et al., 1990; Urschel and Hulsebosch, 1990), and/or to release other growth factors. There is evidence that IGF-1 can stimulate regeneration of nociceptive fibers in the adult rat; but significantly, NGF was ineffective in that same study (Kanje et al., 1989).

Recently, it was reported (Bisby and Chen, 1990) that sensory nerve regeneration is impaired in C57BL/Ola mice. The absence of the usual Schwann cell proliferation and macrophage infiltration in degenerating peripheral nerves of these mice (Lunn et al., 1989) led to the suggestion that axonal regeneration failure was related to a deficit in NGF production in the degenerating pathway (Brown et al., 1991). However, the same argument could apply to other hypothesized growth-promoting molecules. For example, those DRG neurons that do not appear to display high-affinity binding of NGF (Verge et al., 1989), but presumably participate in the usual axonal regeneration after peripheral nerve crush, must also have failed to regenerate in the Ola mice. Equally relevant, their motor axons also show an impaired regeneration (Bisby and Chen, 1990; but see Lunn et al., 1989). Finally, in normal adult rats, regeneration has been reported to occur through as much as $15 \mathrm{~mm}$ of degenerated peripheral nerve rendered totally acellular by repeated freeze/thawing (Sketelj et al., 1989). We suggest, therefore, that the interesting observations from the Ola mice do not negate our conclusions, which is based on the evidence provided in the present report, that sensory nerve regeneration is essentially NGF independent.

\section{The significance of the difference in $N G F$ dependency of regenerating and collaterally sprouting nerves}

In certain respects regeneration resembles both the initial outgrowth of axons during development, and their later dramatic elongation in the enlarging animal (see below). The observations of Davies et al. (1987) are especially pertinent, indicating that the initial outgrowth of trigeminal sensory axons is unlikely to be NGF dependent (see also Lumsden and Davies, 1983). Con- ceivably in the developing nervous system a great deal of axonal growth could be essentially nonselective, promoted by a battery of influences, including the provision of appropriately oriented pathways (e.g., Rogers et al., 1983; Hall et al., 1987; Riggott and Moody, 1987; Letourneau et al., 1988; see also Purves and Lichtman, 1985; Dodd and Jessell, 1988). Similar considerations apply to axonal regeneration in the mature organism. Damaged axons, peripheral (Simpson and Young, 1945) and central (So and Aguayo, 1985), will regenerate in an apparently nonselective manner along at least one pathway, namely, a degenerating segment of peripheral nerve. The NGF independence of sensory nerve regeneration now described is in keeping with these observations.

The present findings add to the now extensive list of often striking differences between regeneration and collateral sprouting. For example, in adult mammals the $\mathrm{A} \alpha$ mechanosensory axons do not undergo collateral sprouting (see Diamond et al., $1992 \mathrm{~b}$ ), even for the 100 or so micrometers needed to innervate neighboring denervated Merkel cells within a single touch dome (Yasargil et al., 1988). However, A $\alpha$-axons regenerate, and even during anti-NGF treatment (Diamond, Foerster, Holmes, and Coughlin, unpublished observations) recognize and reinnervate denervated Merkel cells. A remarkable contrast to these peripheral findings is seen in the adult mammalian CNS, where the collateral sprouting of spared fibers is a common finding (Cotman et al., 1981; Tsukahara, 1981; but see, e.g., Pubols and Bowen, 1988; McMahon and Kett-White, 1991), while spontaneous axonal regeneration has been observed only under special conditions (Foerster, 1982, 1988).

Interestingly, during a rat's growth from approximately 1 month to maturity, the length of the cutaneous axons increases about eightfold. Anti-NGF treatment within this period certainly does not prevent this elongation (Diamond, Foerster, Holmes, and Coughlin, unpublished observations), which we regard as akin to regeneration. Collateral sprouting of lowthreshold A $\alpha$-fibers does occur in the very young rat, however (Jackson and Diamond, 1984), and a curious phenomenon is that this sprouting, and that of the analogous fibers in the adult salamander (Macintyre and Diamond, 1981), is largely confined to the territory of the parent dermatome of the axons, while the regeneration of the same nerves is not; that is, regenerating fibers will readily invade the denervated skin of a neighboring dermatome.

Arriving regenerating axons often "displace" resident terminals that had earlier sprouted from undamaged axons (discussed in Diamond, 1982). For nociceptive nerves this competitive feature (Devor et al., 1979) becomes especially interesting, given the different growth factor dependency of the two growth responses. Regenerating nociceptive axons probably have NGF-R (Verge et al., 1989), but in much reduced numbers (Raivich et al., 1991). Even so, the NGF they might acquire could very well be utilized for purposes other than axonal extension (e.g., Calissano et al., 1984; Chalazonitis et al., 1987; Winter et al., 1988). There are no a priori grounds for supposing that the different functions of NGF will all be expressed at one and the same time (Greene, 1984).

Our findings may have a therapeutic relevance. For example, it may be inappropriate to use sprouting agents when the regeneration of long fiber tracts is the objective, as after spinal cord injuries. However, the results indicate that even a nonselective regeneration drive might achieve a functionally useful result, provided that the regeneration pathways came close 
enough to the appropriate end sites or targets of the axons involved (cf. Keirstead et al., 1989).

\section{Conclusion}

The contrasts between collateral sprouting and axonal regeneration are consistent with the notion (e.g., Diamond, 1988) that the biological functions of these two growth behaviors are basically different. Sprouting is largely concerned with the establishment and maintenance of terminal fields within target tissues. The sprouting phenomenon may be involved in a dynamic turnover of endings in the adult animal, and be one basis for plasticity in the nervous system (Diamond et al., 1988). Our evidence (Diamond et al., 1992a) that impulse activity can prime sensory neurons to the sprouting stimulus of NGF is consistent with these views. On the other hand, regeneration, like the initial outgrowth of axons, has the role (a reparative one in the case of regeneration) of ensuring that neurons project to particular regions or target tissues. We found no evidence that regeneration was enhanced by impulse activity. Given these striking distinctions between collateral sprouting and axonal regeneration, it is not surprising that different growth stimuli might be involved in evoking them, even for the same neuron.

\section{References}

Allt G (1976) Pathology of the peripheral nerve. In: The peripheral nerve (Landon DN, ed), pp 666-739. London: Chapman and Hall.

Assouline JG, Bosch P, Lim R, Kim IS, Jensen R, Pantazis NJ (1987) Rat astrocytes and Schwann cells in culture synthesize nerve growth factor like neurite-promoting factors. Dev Brain Res 31:103-118.

Bandtlow CE, Heumann R, Schual ME, Thoenen H (1987) Cellular localization of nerve growth factor synthesis by in situ hybridization. EMBO J 6:891-899.

Bisby MA, Chen S (1990) Delayed Wallerian degeneration in sciatic nerves of $\mathrm{C} 57 \mathrm{BL} / 01$ a mice is associated with impaired regeneration of sensory axons. Brain Res 530:117-120.

Brown MC, Perry VH, Lun ER, Gordon S, Heumann R (1991) Macrophage dependence of peripheral sensory nerve regeneration: possible involvement of nerve growth factor. Neuron 6:359-370.

Calissano P, Cattaneo A, Aloe L, Levi-Montalcini R (1984) The nerve growth factor (NGF). In: Hormonal proteins and peptides, Vol $12(\mathrm{Li}$ $\mathrm{CH}$, ed), pp 1-56. Orlando, FL: Academic.

Campenot RB (1982) Development of sympathetic neurons in compartmentalized cultures. 1. Local control of neurite growth by nerve growth factor. Dev Biol 93:1-12.

Chalazonitis A, Peterson ER, Crain SM (1987) Nerve growth factor regulates the action potential duration of mature sensory neurons. Proc Natl Acad Sci 84:289-293.

Cotman CW, Nieto-Sampedro M, Harris EW (1981) Synapse replacement in the nervous system of adult vetebrates. Physiol Rev 61:684784.

Davies AM, Bandtlow C, Heumann R, Korshing S, Rohrer H, Thoenen $H$ (1987) Timing and site of nerve growth synthesis in developing skin in relation to innervation and expression of the receptor. Nature 326:353-358.

de la Motte DJ, Allt G (1976) Crush injury to peripheral nerve: an electron microscope study employing horseradish peroxidase. Acta Neuropathol (Berl) 36:9-19.

Devor M, Schonfeld D, Zeltzer Z, Wall PD (1979) Two modes of cutaneous reinnervation following peripheral nerve injury. J Comp Neurol 185:211-220.

Diamond J (1982) Modelling and competition in the nervous system: clues from the sensory innervation of skin. In: Current topics in developmental biology, Vol 17 (Moscana AA, Monroy A, eds), pp 147-205. New York: Academic.

Diamond J (1988) Nerve growth factor and the reinnervation of skin after peripheral nerve lesions. In: Post-lesion neural plasticity (Flohr H, ed), pp 35-47. Berlin: Springer.

Diamond J, Coughlin M, Macintyre L, Holmes M, Visheau B (1987) Evidence that endogenous NGF is responsible for the collateral sprouting, but not the regeneration, of nociceptive axons in adult rats.

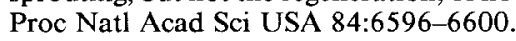

Diamond J, Holmes M, Visheau B (1988) NGF-regulated plasticity in the adult nervous system. Soc Neurosci Abstr 14:245.6.

Diamond J, Holmes M, Coughlin M (1992a) Endogenous NGF and nerve impulses regulate the collateral sprouting of sensory axons in the skin of the adult rat. J Neurosci 12:1454-1466.

Diamond J, Gloster A, Kitchener P (1992b) Regulation of the sensory innervation of skin: trophic control of collateral sprouting. In: Sensory neurons: diversity, development and plasticity (Scott $S$, ed), in press. New York: Oxford.

Dodd J, Jessell TM (1988) Axon guidance and the patterning of neuronal projections in vertebrates. Science 242:692-699.

Doucette R, Diamond J (1987) The normal and precocious sprouting of heat nociceptors in the skin of adult rats. J Comp Neurol 261:592603.

Doucette R, Theriault E, Diamond J (1987) Regionally selective elimination of cutaneous thermal nociception in rats by neonatal capsaicin. J Comp Neurol 261:583-591.

Finn PJ, Ferguson IA, Renton FJ, Rush RA (1986) Nerve growth factor immunohistochemistry and biological activity in the rat iris. $J$ Neurocytol 15:169-176.

Foerster AP (1982) Spontaneous regeneration of cut axons in adult rat brain. J Comp Neurol 210:335-356.

Foerster AP (1988) Return of function after optic tract lesions in adult rats: spontaneous axonal regeneration? In: Post-lesion neural plasticity (Flohr H, ed), pp 473-479. Berlin: Springer.

Greene LA (1984) The importance of both early and delayed responses in the biological actions of nerve growth factor. Trends Neurosci 7 : 91-94.

Hagg T, Gulati AK, Behzadian M, Vahlsing HL, Varon S, Manthorpe M (1991) Nerve growth factor promotes CNS cholinergic axonal regeneration into acellular peripheral nerve grafts. Exp Neurol 112 78-88.

Hall DE, Neugebauer M, Reichardt LF (1987) Embryonic neural retinal cell response to extracellular matrix proteins: developmental changes and effects of the cell substratum attachment antibody. J Cell Biol 104:623-634.

Heumann R, Lindholm D, Bandtlow C, Meyer M, Radeke MJ, Misko TP, Shooter E, Thoenen T (1987a) Differential regulation of mRNA encoding nerve growth factor and its receptor in rat sciatic nerve during development, degeneration and regeneration: role of macrophages. Proc Natl Acad Sci USA 84:8735-8739.

Heumann R, Korshing S, Bandtlow C, Thocnen H (1987b) Changes of nerve growth factor synthesis in non-neuronal cells in response to sciatic nerve transection. J Cell Biol 104:1623-1631.

Hollowell JP, Villadiego A, Rich KM (1990) Sciatic nerve regeneration across gaps within silicone chambers: long-term effects of NGF and consideration of axonal sprouting. Exp Neurol 110:45-51.

Horch K (1979) Guidance of regrowing sensory axons after cutaneous lesions in the cat. J Neurophysiol 42:1437-1449.

Ide C, Kato S (1990) Peripheral nerve regeneration. Neurosci Res [Suppl] 13:S157-S164.

Jackson PC, Diamond J (1984) Temporal and spatial constraints on the collateral sprouting of low-threshold mechanosensory nerves in the skin of rats. J Comp Neurol 226:336-345.

Johnson EM, Taniuchi M, Clark HB, Springer JE, Koy S, Tayrien MW, Loy $\mathbf{R}$ (1987) Demonstration of the retrograde transport of nerve growth factor receptor in the peripheral and central nervous system. J Neurosci 7:923-929.

Kanje M, Skottner A, Sjoberg J, Lundborg G (1989) Insulin-like growth factor I (IGF-I) stimulates regeneration of the rat sciatic nerve. Brain Res 486:396-398.

Keirstead SA, Rasminsky M, Fukuda Y, Carter DA, Aguayo AJ (1989) Electrophysiologic responses in hamster superior colliculus evoked by regenerating retinal axons. Science 246:255-257.

Kenins P (1981) Identification of the unmyelinated sensory nerves which evoke plasma extravasation in response to antidromic stimulation. Neurosci Lett 25:137-141.

Letourneau P, Madsen AM, Palm SM, Furcht LT (1988) Immunoreactivity for laminin in the developing ventral longitudinal pathway of the brain. Dev Biol 125:135-144.

Lindsay RM (1988) Nerve growth factors (NGF, BDNF) enhance axonal regeneration but are not required for survival of adult sensory neurons. J Neurosci 8:2394-2405.

Lumsden A, Davies A (1983) Earliest sensory nerve fibres are guided 
to peripheral targets by attractants other than nerve growth factor. Nature 306:786-789.

Lunn ER, Perry VH, Brown MC, Rosen H, Gordon S (1989) Absence of Wallerian degeneration does not hinder regeneration in peripheral nerve. Eur J Neurusci 1:27-33.

Macintyre L, Diamond J (1981) Domains and mechanosensory nerve fields in salamander skin. Proc R Soc Lond [Biol] 211:471-499.

McMahon SB, Kett-White R (1991) Sprouting of peripheral regenerating primary sensory neurons in the adult central nervous system. J Comp Neurol 304:307-315.

Mearow K, Ross G, Kril Y, Gloster A, Holmes M, Diamond J (1991) Changes in NGF recptor and GAP43 mRNA associated with collateral sprouting and regeneration of dorsal cutaneous nerves in the rat Soc Neurosci Abstr 17:1312.

Nixon BJ, Doucette R, Jackson P, Diamond J (1984) Impulse activity evokes precocious sprouting of nociceptive nerves into denervated skin. Somatosens Res 2:97-126.

Olsson Y (1966) Studies on vascular permeability in peripheral nerves. I. Distribution of circulating fluorescent serum albumin in normal, crushed and sectioned rat sciatic nerves. Acta Neuropathol (Berl) 7: $1-15$.

Olsson Y (1967) Phylogenetic variations in vascular permeability of peripheral nerves to serum albumin. Acta Pathol Microbiol Scand 69:621-623.

Olsson Y (1971) Studies on vascular permeability of peripheral nerves. IV. Distribution of intravenously injected protein tracers in the peripheral nerves of various species. Acta Neuropathol (Berl) 17:114126.

Pubols LM, Bowen DC (1988) Lack of central sprouting of primary afferent fibres after ricin deafferentation. J Comp Neurol 275:282287.

Purves D, Lichtman JW (1985) Geometrical differences among homologous neurons in mammals. Science 228:298-302.

Raivich G, Hellweg R, Kreutzberg GW (1991) NGF receptor-mediated reduction in axonal NGF uptake in retrograde transport following sciatic nerve injury and during regeneration. Neuron 7:151-164.

Rich KM, Alexander TD, Pryor JC, Hollowell JP (1989) Nerve growth factor enhances regeneration through silicon chambers. Exp Neurol 105:162-170.

Rich KM, Yip HK, Osborne PA, Schmidt RE, Johnson EM (1984) Role of nerve growth factor in the adult dorsal root ganglion neuron and its response to injury. J Comp Neurol 230:110-118.

Richardson PM, Riopelle RJ (1984) Uptake of nerve growth factor along peripheral and spinal axons of primary sensory neurons. J Neurosci 4:1683-1689.

Riggott MJ, Moody SA (1987) Distribution of laminin and fibronectin along peripheral trigeminal axon pathways in the developing chick. J Comp Neurol 258:580.

Rogers SL, Letourneau PC, Palm SL, McCarthy J, Furcht LT (1983) Neurite extension by peripheral and central nervous system neurons in response to substratum-bound fibronectin and laminin. Dev Biol 98:212.
Sandrock AW, Matthew WD (1987) Substrate bound nerve growth factor promotes neurite growth in peripheral nerve. Brain Res 425: 360-363.

Seitz RJ, Reiner K, Himmelmann F, Heininger K, Hartung HP, Toyka KU (1989) The blood-nerve barrier in Wallerian degeneration: a sequential long-term study Muscle Nerve 12:627-635.

Simpson SA, Young JZ (1945) Regeneration of fiber diameter after cross unions of visceral and somatic nerves. J Anat 79:48-65.

Sketelj J, Bresjanac M, Popovic M (1989) Rapid growth of regenerating axons across the segments of sciatic nerve devoid of Schwann cells. J Neurosci Res 24:153-162.

So KF, Aguayo AJ (1985) Lengthy regrowth of cut axons from ganglion cells after peripheral nerve transplantation into the retina of adult rats. Brain Res 328:349-354.

Sparrow JR, Kiernan JA (1981) Endoneurial vascular permeability in degenerating and regenerating peripheral nerves. Acta Neuropathol (Berl) 53:181-188.

Stoeckel K, Schwab M, Thoenen H (1975) Specificity of retrograde transport of nerve growth factor (NGF) in sensory neurons: a biochemical and morphological study. Brain Res 89:1-14.

Sutter A, Riopelle RJ, Harris-Warrick RM, Shooter EM (1979) Nerve growth factor receptors: characterization of two distinct classes of binding sites on chick embryo sensory ganglion cells. J Biol Chem 254:5972-5982.

Taniuchi M, Clark HB, Johnson EM (1986) Induction of nerve growth factor receptor in Schwann cells after axotomy. Proc Natl Acad Sci USA 83:4094-4098.

Taniuchi M, Clark HB, Schucitzer JB, Johnson EM Jr (1988) Expression of nerve growth factor receptors by Schwann cells of axotomized peripheral nerves: ultrastructural location, suppression by axonal contact binding properties. J Neurosci 8:664-681.

Theriault E, Diamond J (1988) Nociceptive cutaneous stimuli evoke localized contractions in a skeletal muscle. J Neurophysiol 60:446462.

Tsukahara N (1981) Synaptic plasticity in the mammalian nervous system. Annu Rev Neurosci 4:351-379.

Urschel B, Hulsebosch CE (1990) Schwann cell-neuronal interactions in the rat involve nerve growth factor. J Comp Neurol 296:114-122.

Verge VMK, Riopelle RJ, Richardson PM (1989) Nerve growth factor receptors on normal and injured sensory neurons. J Neurosci 9:914922.

Wadhwani K, Latker C, Balbo A, Rapoport S (1989) Perineurial permeability and endoneurial edema during Wallerian degeneration of the frog peripheral nerve. Brain Res 493:231-239.

Winter J, Forbes A, Sternberg J, Lindsay R (1988) Nerve growth factor (NGF) regulates adult rat cultured dorsal root ganglion neuron responses to the excitotoxin capsaicin. Neuron 1:973-981.

Yasargil GM, Macintyre L, Doucette R, Visheau B, Holmes M, Diamond J (1988) Axonal domains within shared touch domes in the rat: a comparison of their fate during conditions favoring collateral sprouting and following axonal regeneration. J Comp Neurol 270: 301-312. 